\title{
Caracterização técnico-produtiva do sistema de cultivo de palma forrageira no Cariri paraibano
}

\section{José Thyago Aires Souza ${ }^{1}$, Maria das Graças Rodrigues do Nascimento ${ }^{1}$, Janailson Pereira de Figueredo $^{1}$, Fábio Agra de Medeiros Nápoles², Francisco Hélio Alves de Andrade ${ }^{3}$}

${ }^{1}$ Programa de Pós-Graduação em Agronomia, Centro de Ciências Agrárias, Universidade Federal da Paraíba, Areia, Paraíba, Brasil. E-mail: thyago.agro@hotmail.com,graca.agronomia@gmail.com, janailsondfigueredo@ hotmail.com

${ }^{2}$ Centro de Ciências Agrárias e Ambientais, Universidade Estadual da Paraíba, Lagoa Seca, Paraíba, Brasil. E-mail: fnapoles@uol.com.br

${ }^{3}$ Universidade Federal de Lavras, Lavras, Minas Gerais, Brasil. E-mail: helioalvesuepb@ gamil.com

Recebido: 21/05/2017; Aceito: 04/02/2019.

\section{RESUMO}

Objetivou-se analisar o sistema técnico-produtivo da cultura da palma forrageira (Opuntia ficus-indica Mill) em Taperoá, estado da Paraíba, Brasil. Foi realizada uma pesquisa qualitativa e quantitativa através de questionários no segundo semestre de 2013, envolvendo 50 produtores rurais. $80 \%$ dos produtores produzem suas próprias mudas, $66 \%$ fazem a primeira colheita após quatro anos de cultivo, $60 \%$ não utilizam consórcio, não recebem assistência técnica e não comercializam palma forrageira. O esterco bovino é a fonte de adubação orgânica mais utilizada (54\%), 100\% não utilizam análise de solo, 74\% dos solos cultivados com palma forrageira são argilosos.

Palavras-chave: alimentação animal; cactácea; forragem; semiárido.

\section{Technical-produtive characterization of forage cactus cultivation system in Cariri paraibano}

\begin{abstract}
This study aimed to analyze the technical and productive system of forage cactus culture (Opuntia ficus-indica Mill) in Taperoá, Paraíba State, Brazil. Research was carried out qualitative and quantitative through questionnaires in the second half of 2013, involving 50 farmers. $80 \%$ of producers produce their own seedlings, $66 \%$ make the first harvest after four years of cultivation, $60 \%$ do not use consortium, does not receive technical assistance and do not sell forage cactus. The cattle manure is the source of most commonly used organic fertilization (54\%), 100\% do not use soil analysis, $74 \%$ of soils cultivated with forage cactus are clayey.
\end{abstract}

Keywords: animal feed; cactos; forage; semiarid. 


\section{Introdução}

A região semiárida do nordeste do Brasil se caracteriza pela má distribuição das chuvas no tempo e no espaço, apresentando um período de estiagem que ocorre de setembro a dezembro, e um período chuvoso, de março a junho, representado por chuvas de alta intensidade e de curta duração, resultando em elevado risco de perda de solo. As atividades de agricultura de sequeiro na região se iniciam com as primeiras chuvas do ano, coincidindo com o período de ocorrência de chuvas erosivas (Silva Jr. et al., 2011).

A palma forrageira (Opuntia fícus indica) tem origem mexicana é, hoje, uma cactácea totalmente incorporada à paisagem do Nordeste semiárido brasileiro. Introduzida na região em meados do século XIX para servir de suporte alimentar da cochonilha, a mesma expandiu-se e ocupou progressivamente o espaço regional (Gava e Lopes, 2012).

Está cactácea destaca-se pela elevada eficiência de uso da água, uma vez que a proporção é de aproximadamente 50:1, ou seja, $50 \mathrm{~kg}$ de água para cada quilograma de massa seca produzida, enquanto as plantas C3 e C4 apresentam eficiência por volta de 1000:1 e 500:1, respectivamente. Estas relações são valores médios e a eficiência no uso da água pode ser variável, dependendo das condições locais (Silva et al., 2010; Silva et al., 2015).

A maior utilidade desta cultura é na alimentação animal, principalmente nas épocas secas, onde o alimento é escasso e muitas vezes a palma se apresenta como uma das únicas fontes alimentícias, pois apresenta resistência a estiagens prolongadas, fornecendo energia, água e vitamina A, garantindo o suprimento de alimentos para a manutenção dos rebanhos (Barreto et al., 2012). Pode também ser utilizada na prevenção contra a degradação ecológica de ambientes sensíveis e recuperação de áreas degradadas.

Os sistemas de produção de palma são influenciados por diversos aspectos, tais como: variáveis climáticas, atributos do solo, disponibilidade de adubo orgânico, níveis e fontes dos adubos, pragas e doenças, cultivo consorciado ou solteiro e espaçamento utilizado, dentre outros (Farias et al., 2005; Dubeux Júnior et al., 2013; Silva et al., 2015). No entanto, o bom rendimento para a cultura está climaticamente relacionado a áreas com índices pluviométricos de 400 a $800 \mathrm{~mm}$ anuais, umidade relativa acima de $40 \%$ e temperaturas entre 18 e $38{ }^{\circ} \mathrm{C}$ (Pinheiro et al., 2014; Queiroz et al., 2015).

A pesquisa participativa tem sido utilizada, cada vez mais, por diversas entidades e organizações em processos de planejamento rural, como também pelos agentes financiadores, diante da necessidade de conhecer a perspectiva das comunidades locais quanto aos seus principais problemas, bem como sua avaliação quanto ao impacto de programas e projetos de desenvolvimento (Leite et al., 2014).

Diante do exposto, objetivou-se com este trabalho analisar o sistema técnico-produtivo da cultura da palma forrageira no município de Taperoá - PB.

\section{Material e Métodos}

O Município de Taperoá - PB (Figura 1) está localizado na microrregião do Cariri Ocidental $\left(7^{\circ} 12^{\prime}\right.$ 23" Sul - 36 49' 25" Oeste), região central do estado da Paraíba, inserido na unidade geoambiental do Planalto da Borborema (IBGE, 2010).

De acordo com a classificação de Koppen, no município de Taperoá predomina o clima do tipo Bsh: semiárido quente, que abrange a área mais seca do estado. Nos seus aspectos climáticos, a região está caracterizada por chuvas concentradas em um único período (3 a 5 meses), variando as médias anuais de 400 a $800 \mathrm{~mm}$. As temperaturas médias anuais são elevadas (23 a $\left.27^{\circ} \mathrm{C}\right)$. A insolação apresenta média anual de

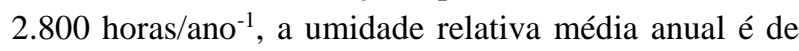
$50 \%$ e a evaporação média anual é de $2.000 \mathrm{~mm} / \mathrm{ano}^{-1}$ (Lima e Rodrigues, 2005).

Este trabalho tratou-se de uma pesquisa qualiquantitativa realizada no segundo trimestre de 2013, envolvendo 50 produtores rurais com faixa etária de 30 a 60 anos de idade do município de Taperoá - PB, na qual foram realizadas entrevistas através de questionários aplicados em visitas às propriedades, onde foi possível observar os campos de palma forrageira bem de perto, aumentando assim a interação e a troca de informações entre os produtores e os pesquisadores e vice-versa.

Durante a pesquisa, foram levantados questionamentos sobre: período de implantação da cultura, efetuação da primeira colheita, aquisição de mudas, utilização de consórcio, utilização de outras cactáceas como fonte de arraçoamento animal, cultivo de outras forrageiras nas propriedades, assistência técnica, comercialização de palma forrageira, forma de adubação orgânica e química, utilização de análise de solo e textura dos solos cultivados com palma forrageira.

Estas questões analisadas são de suma importância para a identificação dos problemas existentes nas propriedades e consequentemente para uma tomada de decisão por parte das entidades públicas ou não, como associações de produtores rurais.

De acordo com a metodologia de Leite et al. (2014), para realização das entrevistas os produtores foram previamente avisados e visitados in loco, buscando sempre a utilização de uma linguagem de fácil entendimento aos agricultores. 


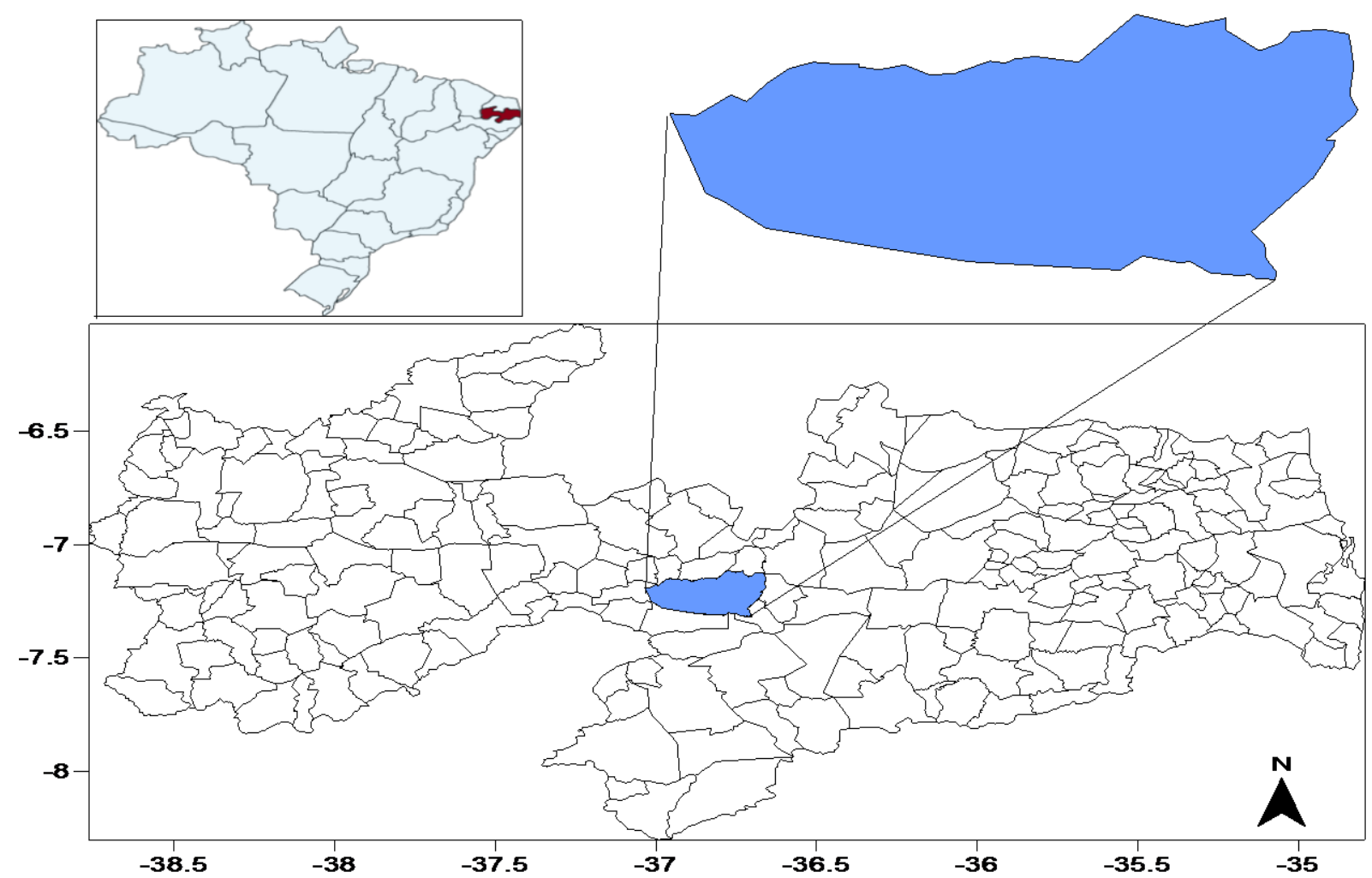

Figura 1. Localização do município de Taperoá - PB.

Não houve interferência nas respostas dadas pelos produtores. Pelo contrário, a incorporação do conhecimento empírico e o respeito às características locais dos produtores nortearam esta pesquisa. As questões e a sequência de perguntas foram idênticas para todos os entrevistados. Todas as entrevistas foram submetidas à crítica para verificação da correção do preenchimento do questionário.

Segundo Marconi e Lakatos (2007), o questionário consiste em um instrumento de coleta de dados constituído por uma série ordenada de perguntas, apresentado por escrito às pessoas, cujo objetivo é proporcionar determinado conhecimento ao pesquisador.

Os dados foram analisados de forma qualitativa e quantitativa, compreendendo assim a triangulação sugerida por Thiollent (1998), o qual afirma que através da triangulação é possível que os dados sejam quantificados e descritos à medida que ocorre a pesquisa. Segundo Minayo et al. (2004), o conjunto de dados qualitativos e quantitativos não se opõe, ao contrário, completa-se, pois a realidade abrangida por ele interage dinamicamente.

Tendo em vista a expressiva quantidade de produtores de palma forrageira presente no município, procurou-se entender a importância da manutenção deste sistema de produção de base familiar, que, por sua vez, é ligado à promoção de desenvolvimento sustentável como meio da fixação do homem no campo.

\section{Resultados e Discussão}

Na região do Cariri paraibano, a palma forrageira é a base alimentar dos rebanhos, principalmente na época da estiagem; apesar disto, alguns produtores não têm o hábito de cultivá-la frequentemente.

$\mathrm{Na}$ Figura 2, podemos constatar que $74 \%$ dos produtores entrevistados implantaram seu palmal há mais de 20 anos, enquanto $6 \%$ cultivam esta cactácea nos períodos entre 0 e 5 e 10 e 15 anos, contudo, 14\% dos produtores afirmaram ter implantado esta cultura entre 05 e 10 anos atrás (Figura 2).

Leite et al. (2014) evidenciaram que a idade média dos palmais nas condições ambientais de quatro municípios na região do Cariri paraibano é superior a nove anos, entretanto, podem existir palmais com mais de 30 anos produzindo fitomassa de qualidade.

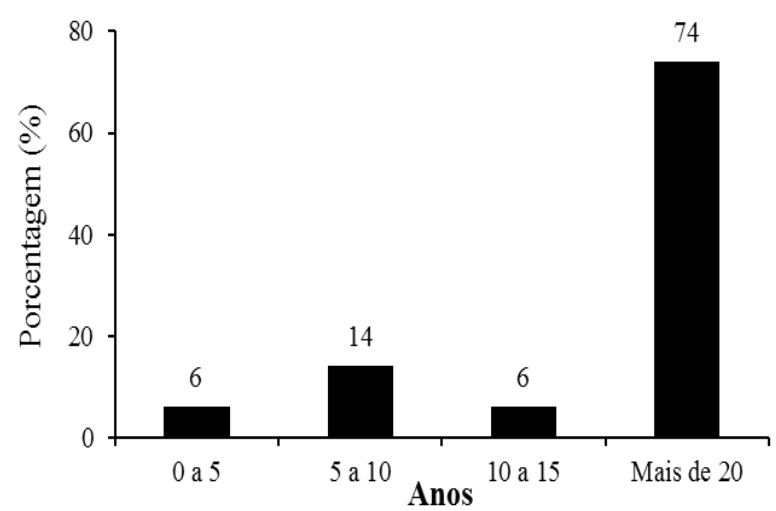

Figura 2. Período de implantação da cultura da palma forrageira na propriedade do município de Taperoá - PB. 
De modo similar, Ramos et al. (2014) caracterizando os sistemas de produção da palma forrageira em Soledade-PB, verificaram que a maioria dos palmais (90,2\%) possui menos de 10 anos de plantio, entretanto na região há áreas com palma forrageira cultivadas há 19 anos de forma ininterrupta.

Na Figura 3, observa-se que $66 \%$ dos produtores que cultivam a palma forrageira efetuam o primeiro corte (colheita de raquetes) após quatro anos da implantação do palmal; este corte, de maneira mais precoce, possibilita maior brotação nos pontos de poda, bem como o planejamento da arquitetura da planta para que acomode o maior número de raquetes ou cladódios. Geralmente o corte é realizado na época da estiagem, ou seja, na época onde há uma grande precariedade de forragem para os rebanhos, sejam eles caprinos, ovinos ou bovinos. No entanto, 34\% dos produtores entrevistados efetuam o primeiro corte da palma forrageira após cinco anos da sua implantação, pois afirmam que aos cinco anos as plantas estão maiores, o que possibilita maior produtividade de fitomassa.

Com relação à aquisição de mudas para multiplicação dos palmais (Figura 4), $80 \%$ dos produtores as adquirem de plantas adultas cultivadas em suas propriedades; no entanto, $20 \%$ adquirem com vizinhos, que, na maioria dos casos, estão iniciando o cultivo de palma forrageira ou possuem palmais com idade entre um e três anos, o que impossibilita o corte para posterior colheita.

Gava e Lopes (2012) destacam que é importante que as raquetes a serem utilizadas para a multiplicação estejam completamente desenvolvidas, saudáveis e isentas de infestações com pragas e doenças, dentre elas, a cochonilha-de-escamas. Após o corte, as raquetes deverão passar por um período de cura à sombra. Nesse período, o cladódio perderá parte da umidade e ocorrerá a cicatrização das lesões provocadas pela operação de corte no campo. O período de cura pode durar entre cinco e dez dias, dependendo do estado inicial de turgidez das raquetes. Salientam ainda que o ponto ideal é aquele que apresenta sinais de perda de turgidez, ficando mais macia à compressão com os dedos e as lesões dos cortes estejam cicatrizadas.

Quanto à utilização de outras culturas em consórcio com a palma forrageira (Figura 5), 40\% dos produtores preferem cultivá-la em sistema solteiro, ou seja, sem a utilização de consórcio; segundo eles, a utilização de qualquer consórcio atrapalha o crescimento e o desenvolvimento desta cactácea. No entanto, 26\% dos produtores consorciam a palma com milho (Zea mays L.), sendo que este serve para o arraçoamento animal na forma de silagem após a moagem da palhada, e a outra parte é utilizada para a produção de grãos, sendo também destinada à alimentação humana nas mais diversas formas de cozimento.

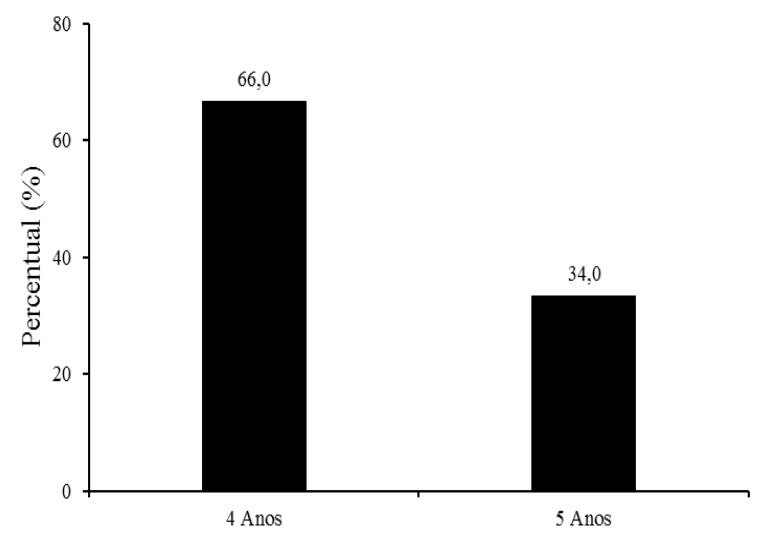

Figura 3. Efetuação da primeira colheita de raquetes em palmais do município de Taperoá - PB.

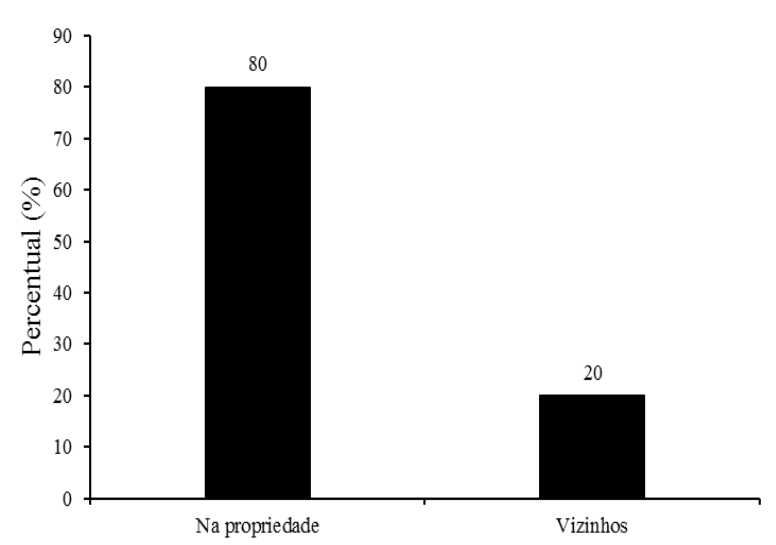

Figura 4. Aquisição de mudas de palma forrageira pelos produtores rurais do município de Taperoá - PB.

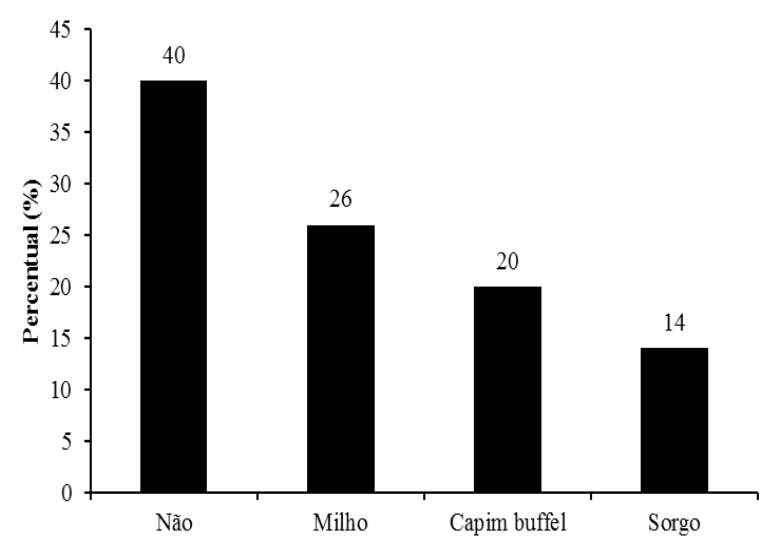

Figura 5. Utilização de consórcio na cultura da palma forrageira por produtores rurais do município de Taperoá - PB.

Constatou-se que 20\% utilizam consórcio com o capim buffel (Cenchrus ciliaris L.) para utilização principalmente na produção de feno para o arraçoamento dos animais na época da estiagem. Apenas 14\% dos produtores utilizam o sorgo forrageiro (Sorghum Vulgare Pers.) no consórcio, o que é muito pouco, considerando que esta gramínea possui uma eficiência fotossintética muito acima da obtida pelo 
milho, o que lhe propicia melhor capacidade de tolerância ao estresse hídrico, problema constante, já que é cultivada na forma de sequeiro e mais ainda na região semiárida com uma média anual de 600 a 700 $\mathrm{mm}$.

Além da palma forrageira, os produtores utilizam outras cactáceas na alimentação de seus rebanhos, sendo que estas, na maioria das vezes, vegetam naturalmente na Caatinga do Cariri paraibano. Neste sentido, observou-se que $34 \%$ dos entrevistados utilizam o xique-xique (Pilosocereus gounellei) para o arraçoamento de seus rebanhos (Figura 6), enquanto $46 \%$ utilizam o Mandacaru (Cereus Jamacaru). Isto acontece devido à maior facilidade de manejo do mandacaru, que não contém tantos espinhos como o xique-xique. No entanto, $14 \%$ utilizam a coroa de frade (Melocactus bahiensis) e 6\% o facheiro (Pilosocereus pachycladus) na alimentação animal; este último é o de mais difícil manejo devido à quantidade, à rigidez e ao tamanho pequeno de seus espinhos. É importante salientar que ambas as cactáceas citadas são mais frequentemente utilizadas nas épocas de estiagem, quando não se tem muitas opções para o arraçoamento dos animais, e que estes percentuais variam conforme a predominância de determinada cactácea em cada propriedade.

Ferreira et al. (2009) ressaltam a importância da utilização de outras cactáceas além da palma forrageira na alimentação dos rebanhos em regiões semiáridas do Nordeste brasileiro, onde particularmente o xique-xique (Pilosocereus gounellei) e o mandacaru (Cereus jamacaru DC.) são utilizados durante períodos de secas prolongadas como um dos principais suportes forrageiros dos ruminantes, suprindo parte da demanda nutricional dos animais, podendo também suprir parte das exigências de água dos mesmos devido ao mecanismo morfofisiológico de economia de água que possuem.

Para que haja produção animal durante todo o ano é necessário otimizar a propriedade para que se produza, além da palma forrageira, outras culturas que possam ser utilizadas na alimentação dos rebanhos. Neste sentido, 46,0\% cultivam o capim elefante (Pennisetum purpureum, Schum) como fonte de alimentação para seus rebanhos (Figura 7), enquanto $10 \%$ preferem o sorgo forrageiro (Sorghum Vulgare Pers.), 8,0\% cultivam diferentes variedades de brachiaria (Brachiaria sp.), $18 \%$ estabelecem o cultivo de capim buffel (Cenchrus ciliaris L.), 14\% o milho (Zea mays L.) e $4 \%$ preferem a Leucena (Leucaena leucocephala).

De acordo com os produtores, as gramíneas de grande porte como campim elefante, sorgo e milho são utilizadas no processo de ensilagem, enquanto as de pequeno porte, como brachiaria, capim buffel e a única leguminosa Leucena são frequentemente utilizadas para a produção de feno.

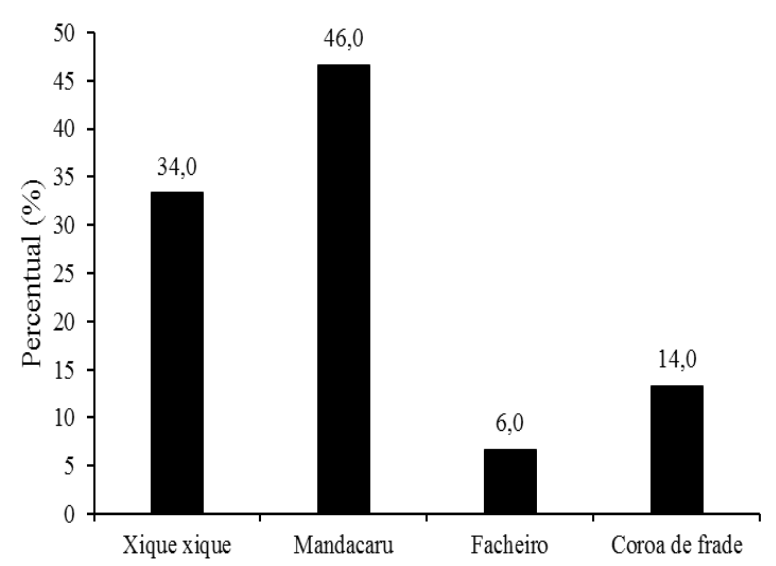

Figura 6. Utilização de outras cactáceas como fonte de alimentação animal no município de Taperoá - PB.

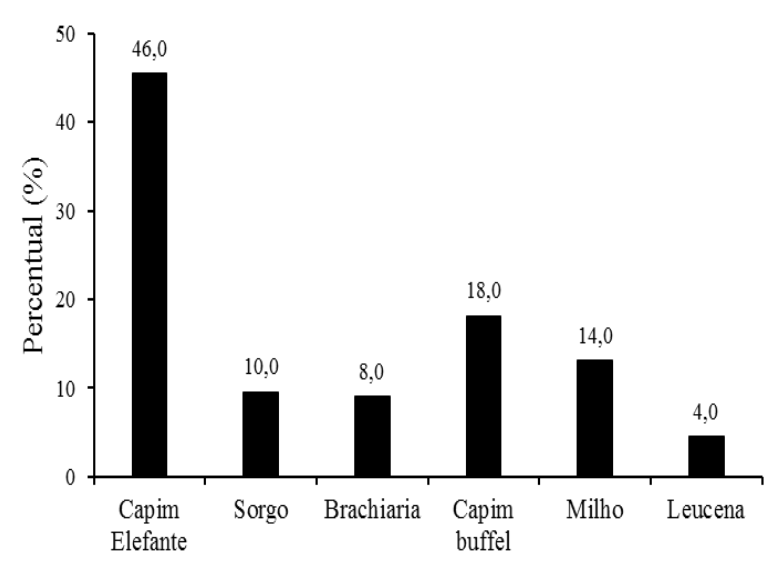

Figura 7. Demais espécies forrageiras cultivadas nas propriedades rurais do município de Taperoá - PB.

A Assistência Técnica e Extensão Rural (ATER) é um dos indicadores mais importantes para a produção agrícola, principalmente no semiárido, onde temos boa parte dos nossos produtores rurais sem escolaridade. Com relação à assistência técnica (Figura 8), 60\% dos produtores entrevistados informaram que não a recebem adequadamente, enquanto $40 \%$ afirmaram ser assistidos por órgãos de ATER de forma satisfatória.

Souza et al. (2015) ressaltam que a ATER é de grande importância dentro do processo de desenvolvimento sustentável, onde o suporte dado nas atividades rurais reflete diretamente em uma maior eficiência na agropecuária, melhorando as condições de trabalho e gerando renda para os produtores do município de Taperoá-PB.

Quando os produtores foram questionados sobre a venda de palma forrageira para aumentar sua renda (Figura 9), 40\% afirmaram que frequentemente comercializam esta cactácea. Segundo eles, este é um bom negócio, pois os custos de produção são baixos 
devido ao fato de esta ser uma cultura que dispensa o frequente uso de insumos. No entanto, $60 \%$ não vendem palma por possuir uma pequena área implantada com esta cultura na propriedade, ou por receio de que haja grandes períodos de estiagem, necessitando da mesma como opção para o forrageamento animal, sendo a palma forrageira, muitas vezes, uma das suas únicas opções para este processo.

A região do Cariri é notadamente uma região com aptidão para a pecuária, principalmente a criação de bovinos, caprinos e ovinos; com isto, há uma geração muito grande de resíduos desta atividade, principalmente estercos, que por ser acessível e muitas vezes sem custo algum para o produtor, torna-se uma excelente fonte de matéria orgânica para a cultura da palma forrageira.

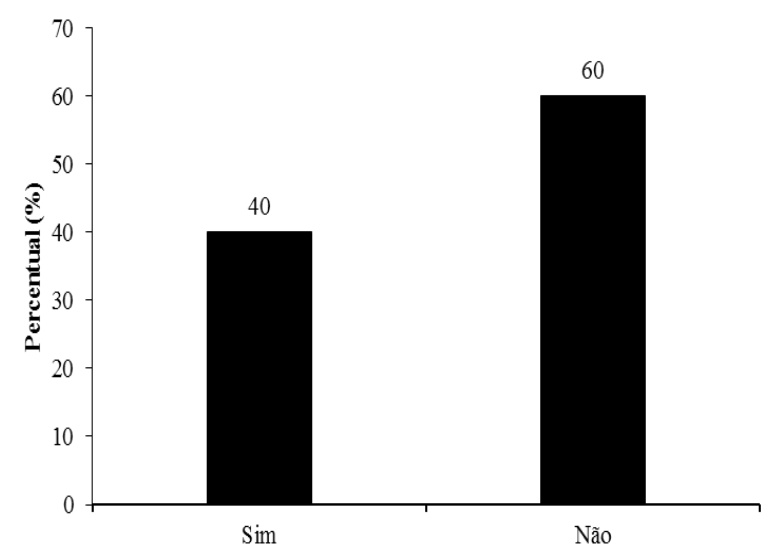

Figura 8. Assistência técnica em palma forrageira obtida pelos produtores rurais do município de Taperoá - PB.

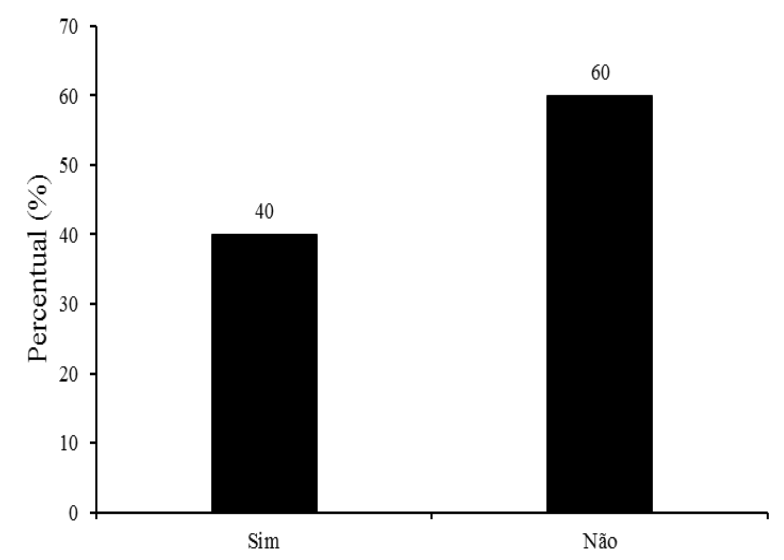

Figura 9. Comercialização de palma forrageira para o aumento da renda familiar por produtores rurais do município de Taperoá - PB.

$\mathrm{Na}$ Figura 10, observa-se que 54\% dos palmais observados utilizam esterco bovino na adubação orgânica da palma forrageira, barateando a produção desta cactácea nas propriedades. $20 \%$ dos entrevistados preferem utilizar na adubação orgânica da palma forrageira os estercos caprino e bovino. Entretanto, 26\% dos produtores utilizam exclusivamente o esterco caprino na adubação orgânica da palma forrageira. Estes produtores também praticam a bovinocultura nas suas propriedades, mas afirmam que com a utilização do esterco caprino consegue-se chegar a resultados mais satisfatórios e de forma mais rápida na produção desta cactácea.

O cultivo da palma forrageira exige do solo boa fertilidade, principalmente em nitrogênio $(\mathrm{N})$, fósforo (P) e potássio (K). Freitas et al. (2012) constataram que no solo, 210 dias após a incorporação, houve maior liberação de $\mathrm{P}$ e $\mathrm{K}$ pelo esterco caprino em relação ao esterco bovino; no entanto, a liberação de $\mathrm{N}$ no esterco bovino foi crescente em todo o intervalo experimental, enquanto no esterco caprino ocorreu uma liberação acentuada nos primeiros trinta dias, seguida de imobilização até os noventa dias.

Quanto à adubação química, 100\% dos produtores afirmam não usá-la, isto devido ao custo elevado em comparação à adubação orgânica, na qual eles praticam com o mínimo de custo possível. Ramos et al. (2014) observaram que $97,6 \%$ dos produtores rurais que cultivam palma forrageira em Soledade-PB utilizam adubação orgânica através do esterco e que na maioria das vezes este esterco é da própria unidade produtiva. Outro dado preocupante é que $100 \%$ dos produtores não realizam análise de solo antes de implantar a cultura da palma forrageira, o que pode prejudicar o crescimento e o desenvolvimento da cultura por conta do excesso ou falta de nutrientes do solo.

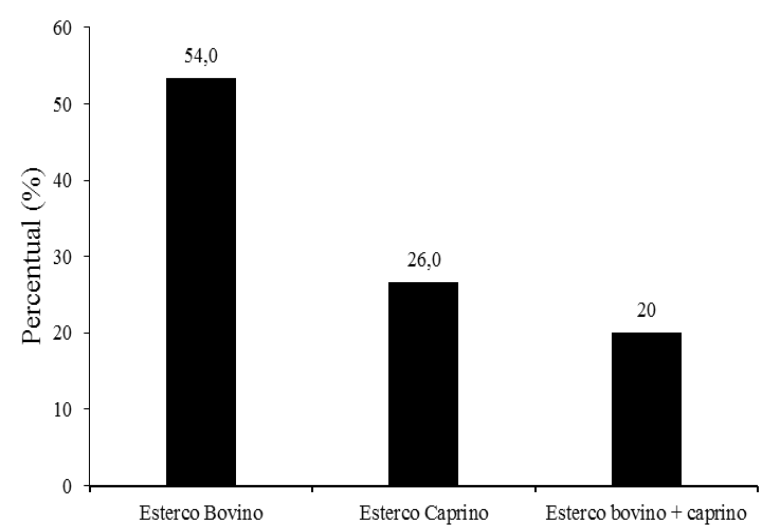

Figura 10. Forma de adubação orgânica adotada para a cultura da palma forrageira no município de Taperoá - PB.

A textura do solo é um dos fatores que deve ser levado em consideração para implantação do palmal, tendo em vista que a maior parte das raízes desta cactácea se concentra nos primeiros $25 \mathrm{~cm}$ de profundidade. Esta é uma das grandes estratégias de sobrevivência e produção desta planta em sistema de sequeiro na região semiárida, o que facilita a absorção de água, mesmo quando as chuvas são em pequena quantidade. 
Na Figura 11, observa-se que $74 \%$ dos solos cultivados com a palma forrageira no município são de textura argilosa, o que favorece a capacidade de retenção e absorção de água mesmo em pluviosidades abaixo da média, levando-se em conta as características radiculares da palma forrageira. Os solos de textura areno-argilosa ocupam $20 \%$ das áreas plantadas com esta cactácea, enquanto $6 \%$ dos produtores afirmaram preferir cultivar esta cactácea em solos de textura arenosa, sendo que este tipo de solo, na maioria das vezes, afeta diretamente a produção pela pouca capacidade de retenção de água, facilitando assim a percolação da água para os horizontes mais adjacentes do solo.

Resultados semelhantes aos deste trabalho foram obtidos por Ramos et al. (2014) no município de Soledade-PB. É importante salientar que na região há um maior percentual de solos argilosos, que geralmente possuem uma maior capacidade de retenção e disponibilidade de água, no entanto, retém água a uma maior tensão com um mesmo conteúdo de água do solo, quando comparado a um solo arenoso (Dubeux Júnior e Santos, 2006).

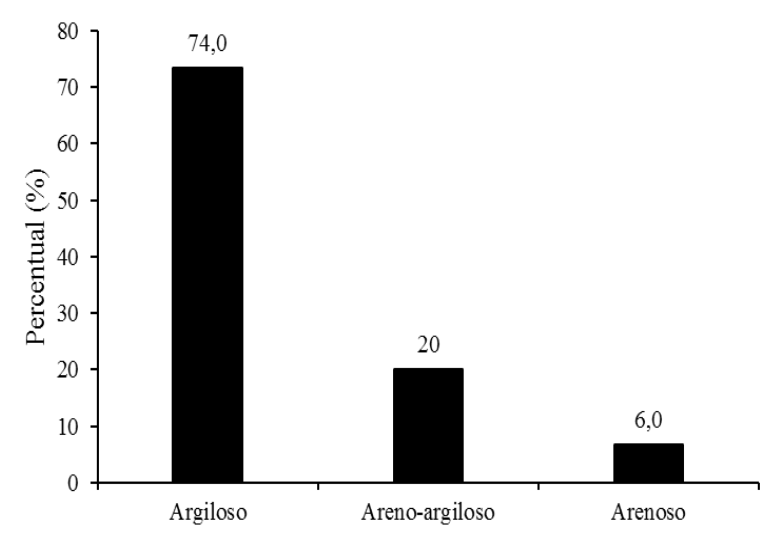

Figura 11. Textura dos solos cultivados com palma forrageira.

\section{Conclusões}

A palma forrageira está absolutamente adaptada às condições edafoclimáticas de Taperoá - PB. A maioria dos produtores produz suas próprias mudas e não utiliza consórcio. A primeira colheita é realizada após quatro anos de cultivo.

O mandacaru (Cereus Jamacaru) e capim elefante (Pennisetum purpureum) são forrageiras bastante utilizadas na alimentação animal. Constatou-se também que a maioria dos produtores não recebe assistência técnica e não comercializa a palma forrageira.

O esterco bovino é a fonte de adubação orgânica mais utilizada pelos produtores, os quais não utilizam análise de solo. O tipo de solo mais comum para o cultivo de palma forrageira é o solo argiloso.

\section{Referências Bibliográficas}

Barreto, H.F.M., Alencar, R.D., Souza, C.M.S., Mesquita, H.C., Pinheiro, K.C., Joaquim, M., Fernandes, M.K.M., Silva, Y.M.O., 2012. Efeito da Fertilização com Urina de Vaca sob as Brotações da Palma Forrageira (Opuntia ficus indica). Revista Científica de Produção Animal, 14, 150-153.

Dubeux Júnior, J.C.B., Santos, M.V.F., 2006. Exigências nutricionais da palma forrageira, in: Menezes, S.C.R., Simões, D.A., Sampaio, E.V.S.B. (Eds.), A palma no Nordeste do Brasil: conhecimento atual e novas perspectivas de uso. Editora Universitária da UFPE, Recife-PE, p. 258-289.

Dubeux Júnior, J.C.B., Santos, M.V.F., Cavalcante, M., Santos, D.C., 2013. Potencial da palma forrageira na América do Sul. Santiago del Estero.

Farias, I., Santos, D.C., Dubeux Júnior, J.C.B., 2005. Estabelecimento e manejo da palma forrageira, in: Menezes, S.C.R., Simões, D.A., Sampaio, E.V.S.B. (Eds.), A palma no Nordeste do Brasil: conhecimento atual e novas perspectivas de uso. Editora Universitária da UFPE, Recife-PE, p. 132-159.

Ferreira, M.A., Silva, F.M., Bispo, S.V., Azevedo, M., 2009. Estratégias na suplementação de vacas leiteiras no Semiárido do Brasil. Revista Brasileira de Zootecnia, 38, 322-329.

Freitas, M.S.C., Araújo, C.A.S., Silva, D.J. 2012. Decomposição e liberação de nutrientes de estercos em função da profundidade e do tempo de incorporação. Revista Semiárido de Visu, 2, 150-161.

Gava, C.A.T., Lopes, E.B., 2012. Produção de Mudas de Palma Forrageira utilizando fragmentos de cladódios. Editora Embrapa, Petrolina.

IBGE, 2010. Censo Populacional. http://www.ibge.gov.br. (Acessado 19 de maio de 2016).

Leite, M.L.M.V., Soares, D.S., Andrade, A.P., Pereira, W.E., Ramos. J.P.F., 2014. Caracterização da produção de palma forrageira no Cariri Paraibano. Revista Caatinga, 27, 192-200.

Lima, J.R., Rodrigues, W., 2005. Estratégia de combate à desertificação. Editora UFCG/ABEAS, Campina Grande.

Marconi, M.A., Lakatos, E.M., 2007. Técnicas de Pesquisa. Editora Atlas, São Paulo.

Minayo, M.C.S., Deslandes, S.F., Cavalcante Neto, O., Gomes, R., 2004. Pesquisa Social: teoria, método e criatividade. Editora Petrópolis, Rio de Janeiro.

Pinheiro, K.M., Silva, T.G.F., Carvalho, H.F.S., Santos, J.E.O., Morais, J.E.F., Zolmier, S., Santos, D.C., 2014. Correlações do índice de área do cladódio com características morfogênicas e produtivas da palma forrageira. Revista Pesquisa Agropecuária Brasileira, 49, 939-947.

Queiroz, M.G., Silva, T.G.F., Zolmier, S., Silva, S.M.S., Lima, L.R., Alves, J.O., 2015. Características morfofisiológicas e produtividade da palma forrageira em diferentes lâminas de irrigação. Revista Brasileira de Engenharia Agrícola e Ambiental, 19, 931-938.

Ramos, J.P.F., Santos, E.M., Freitas, F.F., Cândido, E.P., Lima Júnior, A.C., Leite, M.L.V., Oliveira Júnior, S., 2014. 
Caracterização técnica dos sistemas de produção de palma forrageira em Soledade, PB. Revista AGROTEC, 35, 23-30.

Silva Júnior, V.P., Montenegro, A.A.A., Silva, T.P.N., Guerra, S.M.S., Santos, E.S., 2011. Produção de água e sedimentos em bacia representativa do semiárido pernambucano. Revista Brasileira de Engenharia. Agrícola e Ambiental, 15, 10731081.

Silva, N.G.M., Lira, M.A., Santos, M.V.F., Dubeux Júnior, J.C.B., Mello, A.C.L., Silva, M.C., 2010. Relação entre características morfológicas e produtivas de clones de palmaforrageira. Revista Brasileira de Zootecnia, 39, 2389-2397.
Silva, P.F., Matos, R.M., Borges, V.E., Dantas Júnior, G.J., Dantas Neto, D., 2015. Crescimento e produção de palma forrageira sob fertilização mineral. Journal of Agronomic Sciences, 4, 96-115.

Souza, J.T.A., Farias, A.A., Correia, F.G., Costa, C.A.G., Oliveira, S.J.C., 2015. Associativismo, assistência técnica e extensão rural como políticas públicas para a geração de desenvolvimento sustentável na agricultura familiar em Taperoá-PB. Revista Brasileira de Geografia Física, 8, 303308.

Thiollent, M., 1998. Metodologia de Pesquisa e Ação. Editora Cortez, São Paulo. 